\title{
Determinación del flujo salivar en niños uruguayos portadores de HIV
}

Alvarez $L^{1}$

Hermida $L^{2}$

Fabruccini $A^{3}$

Suárez $G^{4}$

Ourens $M^{5}$

Gutiérrez $E^{6}$

\section{Resumen}

La mayoría de niños infectados por el virus de la inmunodeficiencia humana (VIH) presentan, dentro de sus primeros signos de enfermedad, manifestaciones orales. Uno de los factores a considerar es la disminución del flujo salival producido por infiltración glandular por el propio virus o como efecto secundario a la toma de medicación antiretroviral. Objetivo: Determinar el flujo salival en niños uruguayos portadores de VIH, que asisten al Centro Nacional de Referencia VIH SIDA del Centro Hospitalario Pereira Rossell, (CHPR) en Montevideo-Uruguay. Material y métodos: Se realizó un estudio descriptivo cuantitativo analítico de casos y controles. Se incluyeron todos los pacientes portadores de VIH que asisten al Centro Nacional de Refe- rencia (CHPR) y los pacientes del grupo control eran usuarios del mismo Hospital, con similares condiciones socio-económicas y sanos desde el punto de vista general. Se realizó el recuento de flujo salival. Los niños del grupo de estudio se dividieron a su vez en dos grupos, según su adherencia al tratamiento antirretroviral, que era calificada en buena o mala. Se estudiaron también otros parámetros como hipertrofia parotídea y actividad de caries. Resultados: Se encontró diferencia estadísticamente significativa entre los niños del grupo de estudio y grupo control en relación a flujo salival $(p=0,0002)$, independiente de la adherencia al tratamiento antiretroviral.

Palabras clave: saliva, enfermedades de parótida, niños, HIV.

\section{Artigo Original}

\section{Determinação do fluxo salivar em crianças uruguaias portadoras do HIV}

\section{Resumo}

A maioria das crianças infetadas pelo vírus da imunodeficiência humana (HIV) apresentam, dentro de seus primeiros signos de doença, manifestações orais. Um dos fatores a considerar é a diminuição do fluxo salival produzido por infiltração glandular pelo próprio vírus ou como

${ }^{1}$ Prof Agdo. Facultad de Odontología- Universidad de la República, Montevideo- Uruguay

${ }^{2}$ Ex Asist. $G^{\circ} 2$ Facultad de Odontología UDELAR

${ }^{3}$ Asist. $G^{\circ} 2$ Facultad de Odontología UDELAR

${ }^{4}$ Odontóloga

${ }^{5}$ Odontóloga

${ }^{6}$ Prof Agdo Facultad de Medicina- UDELAR

* Premio a mejor trabajo de investigación. IV reunión anual Sociedad Uruguaya de Investigación en Odontología, División de IADR 
efeito secundário à tomada de medicação antiretroviral. Objetivo: Determinar o fluxo salival em crianças uruguaias portadoras de HIV, que assistem ao Centro Nacional de Referência HIV SIDA do Centro hospitalar Pereira Rossell, em Montevidéu-Uruguai. Material e métodos: Realizo-se um estudo descritivo quantitativo analítico de casos e controles. Incluíram-se todos os pacientes portadores de HIV que assistem ao Centro Nacional de referência (CHPR) e os pacientes do grupo controle eram utentes do MSP, com similares condições sócio-económicas e sãos desde o ponto de vista geral. Realizou-se o reconto de fluxo salival. As crianças do grupo de estudo dividiram-se a sua vez em dois grupos, según seu aderência ao tratamento antirretroviral, qualificada em boa ou ruim. Estudaram-se también outros parámetros como hipertrofia parotídea e actividade de caries. Resultados: Encontró-se diferença estadísticamente significativa entre as crianças do grupo de estudo e grupo controle em relaçãon a fluxo salival $(\mathrm{p}=$ 0,0002), independente da aderência ao tratamento antiretroviral.

Palavras chave: saliva, doença parótida, crianças, HIV.

\title{
Original article
}

\section{Determination of salivary flow on VIH infected uruguayan children}

\begin{abstract}
One of the first signs of disease of most children infected with VIH is oral. Salivary flow can be affected by different situations, such us VIH infection and some antirretroviral medication. Objetivs: The purpose of this study was to determine salivary flow in uruguayan children infected with VIH who attend to the Centro Nacional de Referencia VIH-SIDA del Centro Hospitalario Pereira Rossell, (CHPR) in Montevideo, Uruguay. Materials and methods: A cuantitative analitic descriptive, case control study was performed. All patients attending VIH Service at the CHPR were included, and the control group were children who asked for treatment at the same Hospital, but were not infected with VIH. The salivary flow count up was done. Children of the study group were divided into two groups, according to their adherence about the antirretroviral treatment, qualified in good or bad. There was also registered other parameters

such us parotid's hypertrophy and caries activity. Results: There was found a significant difference between the groups related to the salivary flow ( $p=0,0002)$, independent of adherence to antirretroviral therapy.

Key words: salivary, parotid's disease, children, HIV.

\section{Introducción}

Los niños infectados por el virus de la inmunodeficiencia humana (VIH) presentan, dentro de sus primeros signos de enfermedad, manifestaciones orales ${ }^{1}$. La más frecuente es la candidiasis oral con una prevalencia entre 11 y $72 \%$, según diferentes autores y poblaciones. En el Centro de Referencia Nacional VIH-SIDA, del Centro Hospitalario Pereira Rossell (CHPR), Montevideo, Uruguay, la prevalencia observada fué del $17 \%$. $^{2,3,4,5}$
\end{abstract}


Los principales factores de riesgo que predisponen al desarrollo de dichas manifestaciones orales son: el bajo número de linfocitos T CD4+, la presencia de xerostomía y la ausencia de tratamiento antirretroviral así como la falta de adherencia al mismo. Con la aparición de la terapia medicamentosa, se ha observado una franca disminución en la prevalencia de estas afecciones orales a lo largo de los años. Sin embargo la patología caries dental, independiente de estos factores sigue siendo una patología de alta prevalencia, llevando a la rápida mutilación de la cavidad oral de los pacientes. Valdez y colaboradores en 1994, afirmaron que la caries es la enfermedad bucal más prevalente en estos pacientes, sin poder explicar claramente la vinculación caries dental VIH-SIDA. Loggoti y Costa la vinculan con la presencia de xerostomía ${ }^{7,8}$.

El flujo salival en niños y jóvenes sanos está aumentado respecto a los adultos, lo que muchas veces enmascara las variaciones del mismo. El flujo salival estimulado en niños es de $1 \mathrm{ml} / \mathrm{m}$ en relación a $0.7 \mathrm{ml} / \mathrm{m}$ en los adultos ${ }^{8,9}$. Los niños portadores de la inmunodeficiencia humana presentan en su mayoría afectación de las glándulas salivales, siendo la parótida la glándula más frecuentemente involucrada. Según el autor la hipertrofia de esta glándula se acompaña de un dramático descenso del flujo salival ${ }^{11}$. Este factor unido a la dieta rica en hidratos de carbono, frecuente en estas poblaciones, podrían explicar la alta prevalencia y la severidad de las lesiones de caries en niños. ${ }^{6,7,10}$

El Centro de Referencia Nacional VIH-Sida funciona dentro del Hospital de Niños Pereira Rossell en Montevideo, Uruguay. Allí concurren para su asistencia embarazadas y niños portadores del virus de la inmunodeficiencia humana, siendo asistidos por un equipo interdisciplinario en forma integral y personalizada. A pesar del seguimiento de los niños desde su nacimiento y confirmación de sero positividad, así como la entrega de elementos de higiene dental periódicamente, no ha sido posible controlar la enfermedad caries dental. La población infantil infectada que concurre al CHPR presenta una alta prevalencia de caries, en relación a grupos etarios similares y de similar condición socio-económica. Asistidos dentro de un Programa Educativo-Preventivo-Asistencial, no responden de la misma manera que grupos infantiles sero.negativos ${ }^{4}$. Si bien la prevalencia de caries suele ser similar, en etapas de dentición decidua, la velocidad de avance de las lesiones hace que el índice de caries aumente abruptamente en etapas de dentición mixta. La disminución del flujo salival puede provocar un aumento de la morbilidad durante el desarrollo de la enfermedad, dejándolos más vulnerables a lesiones de la cavidad oral, debido a la carencia de elementos protectores aportados por la saliva. No existen en nuestro país antecedentes que asocien caries dental con flujo salival en niños portadores de VIH, por lo tanto, el propósito del presente estudio fue determinar el flujo salival en niños uruguayos portadores de VIH, que asisten al Centro Nacional de Referencia VIH SIDA, del Centro Hospitalario Pereira Rossell en Montevideo, Uruguay.

\section{Material y Métodos}

Se realizó un estudio cuantitativo analítico de casos y controles en el Centro de Referencia Nacional Obstétrico Pediátrico VIH-Sida del CHPR en Montevideo-Uruguay. Para su realización se obtuvo la aprobación de las autoridades del Centro. Se obtuvo el consentimiento informado de los padres o tutores de los pacientes y el asentimiento de los niños. Todos los participantes fueron incluidos en un Programa Educativo Preventivo Asistencial. 
El grupo de estudio (E) estuvo integrado por la totalidad de niños infectados con VIH que concurrieron al CHPR durante el año 2009. Se excluyeron aquellos niños con discapacidad o que presentaban asociadas otras patologías que podían generar sesgo de confusión. El grupo control (C) se conformó con niños sanos, de ambos sexos, que no estuvieran tomando medicación en el momento de estudio. Los niños de ambos grupos eran de similar situación socioeconómica, usuarios del mismo servicio de salud pública.

Dos examinadores calibrados (Kappa 0.9) realizaron a todos los pacientes un examen bucal completo sistematizado, que fue registrado en una ficha odontológica para establecer los índices CPO/ceo. El examen clínico bucal se realizó con luz ambiental, por observación. Simultáneamente se efectuó palpación parotídea y toma de saliva estimulada en condiciones basales para la cuantificación del flujo salival. La estimulación se realizó utilizando chiclets (gomas de mascar) sin azúcar. Se solicitó al niño que masticara durante 5 minutos el chicle, permitiéndole tragar la saliva. Pasado este tiempo se solicitaba que no tragara y se recolectó la saliva residual de la cavidad bucal en un recipiente milimetrado durante 5 minutos.

Para la medición de los datos se subdividió el grupo de estudio en dos: pacientes con buena adherencia al tratamiento antirretroviral (EB) y pacientes con mala adherencia al tratamiento antirretroviral (EM). La adherencia al tratamiento antirretroviral se definió por consenso, como mala o buena en función del cumplimiento de los controles clínicos, el resultado de la carga viral y la población linfocitaria. Se consideró buena cuando el niño cumplía en forma adecuada los controles clínicos trimestrales, la población linfocitaria era ade- cuada y la carga viral era indetectable o por debajo de 10000cp; se consideró mala cuando el control clínico del niño era irregular, la población linfocitaria estaba disminuida o la carga viral era superior a $10000 \mathrm{cp}^{\prime \prime}$. Los datos fueron evaluados y analizados por la Pediatra del CHPR, aportándolos al equipo de trabajo.

Análisis estadístico: Se utilizó análisis descriptivo, test de normalidad y test no paramétrico Kruskal Wallis. El nivel de significancia fue de $\mathrm{p} \leq 0.05 \%$.

\section{Resultados}

Participaron 66 pacientes, 32 en el grupo de estudio y 34 en el grupo control. El grupo de estudio estuvo conformado por 18 varones y 14 niñas, en edades comprendidas entre 4 y 16 años, con un promedio de 9,34 \pm 3,04 años. El grupo control estuvo integrado por 21 varones y 13 niñas, en edades comprendidas entre 5 y 12 años, con un promedio de edad de $8,44 \pm 2,27$ años. Se comparó la variable actividad de caries y flujo salival en ambos grupos.

La cuantificación del flujo salival mostró diferencia significativa entre grupo E y grupo C (Tabla 1-Gráfico 1). En el contraste de Kruskal-Wallis

\section{Gráfico de Cajas y Bigotes}

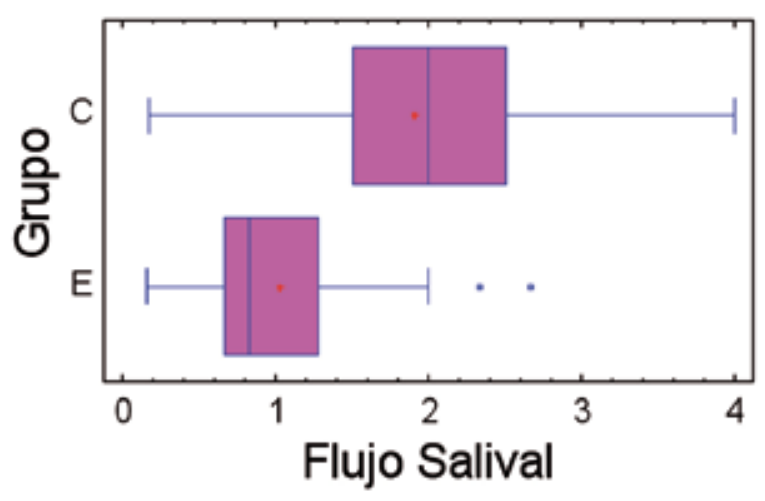

Gráfico 1. Flujo salival según grupo. 
Tabla 1. Cuantificación flujo salival.

\begin{tabular}{|c|l|c|c|c|c|c|}
\hline Grupo & N & Media & Mediana & $\begin{array}{c}\text { Desviación } \\
\text { típica }\end{array}$ & Mínimo & Máximo \\
\hline C & 34 & 1,91294 & 2,0 & 0,870683 & 0,17 & 4,0 \\
\hline E & 32 & 1,02188 & 0,83 & 0,583053 & 0,16 & 2,66 \\
\hline Total & 66 & 1,48091 & 1,33 & 0,865086 & 0,16 & 4,0 \\
\hline
\end{tabular}

Tabla 2. Flujo salival según grupo.

\begin{tabular}{|c|c|c|}
\hline Contraste de & Kruskal-Wallis para Flujo & Salival según Grupo \\
\hline Grupo & Tamano muestral & Rango Promedio \\
\hline c & 34 & 43,25 \\
\hline $\mathbf{E}$ & 32 & 23,1406 \\
\hline Estadistico $=$ & $\mathrm{P}$-valor $=0,000$ & 0202049 \\
\hline
\end{tabular}

Tabla 3. Contraste de Kruskal-Wallis para Flujo Salival según Adherencia

\begin{tabular}{|c|c|c|}
\hline Adherencia & $\begin{array}{c}\text { Tamaño } \\
\text { muestral }\end{array}$ & $\begin{array}{c}\text { Rango } \\
\text { Promedio }\end{array}$ \\
\hline 0 & 13 & 15,7308 \\
\hline 1 & 16 & 14,4063 \\
\hline
\end{tabular}

Estadístico $=0,174244 \quad$ P-valor $=0,676367$

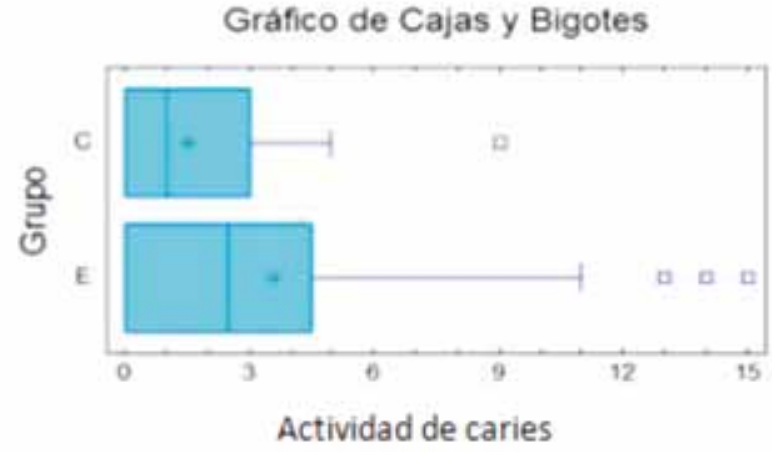

Gráfico 2. Actividad de caries según grupo.

Tabla 4. Resumen de estadísticos actividad de caries por grupo.

\begin{tabular}{|c|c|c|c|c|c|c|}
\hline Grupo & N & Media & Mediana & Desviación típica & Mínimo & Máximo \\
\hline C & 34 & 1,52941 & 1,0 & 2,09234 & 0,0 & 9,0 \\
\hline E & 32 & 3,59375 & 2,5 & 4,35416 & 0,0 & 15,0 \\
\hline Total & 66 & 2,5303 & 1,0 & 3,51358 & 0,0 & 15,0 \\
\hline
\end{tabular}

se confirma esta diferencia $(\mathrm{p}=0.0000202049)$ (Tabla 2).

En el grupo E, los valores de flujo salival en relación a la adherencia al tratamiento antirretro- viral no mostraron diferencias estadísticamente significativas (Tabla 3).

Con respecto a flujo salival en relación a actividad de caries entre los grupos control y estudio 
se encontró diferencia estadísticamente significativa (Tabla 4-Gráfico 2). Se realizó un test de chi-cuadrado para ver si la variable actividad de caries se ajusta a una distribución normal. Dando chi-cuadrado bondad de ajuste $=214,0$ con un $\mathrm{p}$-valor $=0,0$; dado que este $\mathrm{p}$-valor para el test es inferior a 0,01 , podemos rechazar que proceda de una distribución normal.

Realizamos un test de Kruskal-Wallis=4,13975 con un p-valor $=0,0418$, puesto que el $\mathrm{p}$-valor es inferior a 0,05 , hay diferencia estadísticamente significativa entre las medianas de los grupos a un nivel de confianza del $95 \%$.

El examen clínico sobre hipertrofia parotídea no permitió realizar análisis estadístico ya que tan solo 3 niños del grupo de estudio fueron positivos a éste.

\section{Discusión}

En el presente trabajo se observó disminución del flujo salival en el grupo de estudio en relación al grupo control, lo cual había sido sugerido por diferentes autores aunque no se encontró ninguna evidencia que explicara esta asociación. No fue posible en este trabajo encontrar una asociación entre la hipertrofia parotídea y la disminución del flujo salival. Este dato sería fundamental para comprender las causas de esta disminución y poder aplicar medidas preventivas adecuadas.

En el grupo de estudio no se observaron diferencias al comparar el flujo salival en los pacientes con buena o mala adherencia al tratamiento, aunque la muestra no fue suficiente para poder obtener datos concluyentes en este aspecto. Este sería un elemento a tener en cuenta en futuros estudios, ya que descartaría el hecho de que haya una relación directa entre dis- minución de flujo salival y toma de medicación antiretroviral. Así mismo debe considerarse que el tiempo transcurrido desde el comienzo de la toma de la medicación pudo haber tenido un efecto significativo, no tenido en cuenta debido al tamaño de la muestra. Cabe destacar que en nuestro país, el acceso a la medicación por parte de los niños usuarios del Centro de Referencia es gratuita, por lo cual la mala adherencia al tratamiento debería explicarse por otros factores.

La compleja realidad que acompaña a estos niños y su entorno, es un factor determinante para la patología caries dental. Un alto porcentaje de estos pacientes provienen de núcleos familiares disfuncionales (huérfanos, situación de calle, viviendo en hogares sustitutos, etc). A pesar de que el Centro de Referencia facilita el acceso a la asistencia de salud integral por medio de un equipo multidisciplinario, brindando medicación y todo el apoyo necesario para su cuidado, la realidad muestra que en algunos casos esto no es suficiente para lograr el equilibrio deseado. La caries es una enfermedad multifactorial, donde los aspectos psicosociales son determinantes para su manifestación y severidad. Los resultados del presente estudio reafirman los obtenidos en el estudio previo realizado en el mismo Servicio $^{4}$.

\section{Conclusiones}

En el presente estudio el flujo salival en niños $\mathrm{VIH}+$ fue significativamente inferior al grupo control.

Es necesario replicar el presente trabajo en una muestra mayor para permitir inferir los resultados al resto de la población portadora de esta patología. 


\section{Referencias}

1. Falloon J, Eddy, Wiener L, Pizzo P. Human immunodeficiency virus infection in children. J Pediatr 1989; 114: 1-30

2. Expósito A, Vallejo B, Martos A. Manifestaciones orales de la infección por VIH en la infancia: articulo de revisión. Med Oral Patol Oral Cir Bucal 2004; 9: 5. 19.

3. Squassi A, Allessandrello H, Di Eramo I, Piovano S, Bordoni N. Estudio de costos de la atención odontológica en niños infectados con VIH o con SIDA. Bol Asoc Argent Odont Niños 2005; 34 (3): 12-8.;

4. Alvarez L, Hermida L, Cuitiño E. Situación de salud oral de los niños uruguayos portadores del virus de la inmunodeficiencia humana. Arch Pediatr Urug 2007; 78(1): 23-28.

5. Expósito A, Vallejo E, Martos E. Manifestaciones orales de la infección por VIH en la infancia: artículo de revisión. Med oral Patol Oral Cir Bucal 2004; 9:410-20.

6. Hernández M. Manifestaciones orales de la infección por el VIH en odontopediatría. RCOE 1999; 4(2):157-167

7. Loggoti P. Oral manifestations of HIV infection in children.

8. Oral Surg. Oral Med. Oral Pathol 1992; 73: 187-92. 15.

9. Costa I, Villena R, Oral Findings in pediatric AIDS: a case control study in Brazilian children. ASDC journal of dentistry for children 1998; 65: 186-90.).

10. Dawes C. Physiological factors affecting salivary flow rate, oral sugar clearance, and the sensation of dry mouth in man. Journal of Dental Research 1987; 66: 648-653.

11. Dawes C. How much saliva is enough for avoidance of xerostomia? Caries Res. 2004; 38(3):236-40.

12. Walsh L. Dry mouth: a clinical problem for children and young adults. International dentistry sa. Vol $9 \mathrm{n}^{\circ} 52008$.

Fecha de recepción: 11-08-2011

Fecha de aceptación: 29-08-2011

Correspondencia: Licet Alvarez Loureiro- $\underline{\text { licet2001@hotmail.com }}$ 